Kiryoku, Volume 3 No 22019

e-ISSN: 2581-0960 p-ISSN: 2599-0497

Tersedia online di http://ejournal.undip.ac.id/index.php/kiryoku

\title{
OMAMORI DALAM KEPERCAYAAN MASYARAKAT JEPANG
}

\author{
Yuliani Rahmah \\ Program Studi Bahasa dan Kebudayaan Jepang Fakultas Ilmu Budaya Universitas \\ Diponegoro \\ Email : yuliani.rahmah@live.undip.ac.id
}

\begin{abstract}
Abstrak
Omamori merupakan tradisi yang berasal dari kepercayaan animisme dan pantheisme. Kepopuleran omamori yang sudah dikenal sejak zaman Tokugawa dan masih bertahan dalam masyarakat modern Jepang seringkali menimbulkan pertanyaan mengenai apa dan bagaimana bentuk dari jimat ala Jepang tersebut. Dengan studi kepustakaan artikel ini bertujuan untuk memaparkan mengenai keberadaan omamori dalam kepercayaan Jepang yang meliputi definisi, bentuk serta jenis dari omamori tersebut. Omamori pada umumnya berbentuk sebuah kantung kain berdekorasi yang di dalamnya terdapat lipatan kertas atau potongan kayu yang bertuliskan nama dewa dan menyimpan kekuatan dewa tersebut. Dari sekian banyak jenisnya, terdapat 7 jenis omamori yang paling sering digunakan oleh masyarakat Jepang. Ketujuh jenis omamori tersebut dijadikan jimat pelindung untuk setiap tahap dari siklus kehidupan manusia.
\end{abstract}

Kata Kunci: Kepercayaan Masyarakat Jepang; Omamori; Tradisi Keagamaan

\begin{abstract}
(Omamori in Japanese Belief) Omamori known as one of animisn and pantheism 's tradition. Omamori, which has been known since the Tokugawa period, still exist in modern Japanese society as a talisman. Theres some questions about what and how the shape of this Japanese charm is. By using literature study approach this article will describe the existence of omamori in Japanese beliefs which includes the definition, form and type of omamori. Omamori is spiritual charms, talismans and amulets in the Japanese religious tradition that possess the power to ward off misfortune and procure good luck. They can be made of pieces of wood, patches of cloth, strips of paper or rings of metal, and come in various sizes. There are seven types of omamori which are most used by Japanese people. That seven types of omamori are used as protective charms for each stage of the human life cycle.
\end{abstract}

Keywords: Japanese Belief ; Omamori; Religious Tradition

\section{PENDAHULUAN}

Jepang merupakan salah satu negara maju yang dikenal kuat memelihara tradisi dan budaya leluhurnya, salah satunya adalah ideologi yang mereka yakini. Meskipun mempunyai ideologi yang terjaga secara baik, masyarakat Jepang pada umumnya tidak memeluk suatu agama atau kepercayaan tertentu.
Bagi masyarakat Jepang agama nampaknya bukanlah hal penting yang terkait dengan kehidupan keseharian mereka.Hal tersebut didukung pula dengan sikap pemerintah yang memberikan kebebasan bagi masyarakatnya untuk memilih memeluk suatu agama atau bahkan tidak beragama. Dalam undang undang dasar nya disebutkan bahwa pemerintah tidak diizinkan untuk 
mencampuri urusan yang berhubungan dengan keagamaan. Selain itu terdapat larangan keras menggunakan anggaran negara untuk hal-hal yang berhubungan dengan aktifitas keagamaan. Semua lembaga agama tidak boleh diberi hak istimewa dari negara serta tidak diperkenankan melaksanakan kekuatan politik. (Mulyadi,2017;16).

Namun demikian dari data yang dikeluarkan dan direvisi oleh Kementrian Pendidikan Jepang dapat diketahui bahwa jumlah penganut agama di Jepang cukup banyak. Menurut data tersebut masyarakat Jepang yang menjadi penganut Shinto berkisar 107 juta orang, penganut Budha berkisar 89 juta orang, penganut Katolik dan Kristen Protestan sekitar 3 juta orang, serta sekitar 10 juta orang sebagai penganut agama lain-lain. Apabila dijumlahkan maka total seluruh penganut agama di Jepang akan berjumlah 290 juta.

(Herlina,2011: 114)

Dari data di atas dapat dilihat bahwa ajaran agama yang banyak dianut oleh masyarakat Jepang adalah Shinto dan Budha. Shinto dikenal sebagai agama asli masyarakat Jepang, sementara Budha yang datang dan berkembang di Jepang pada sekitar abad ke 6 harus melewati proses penyesuaian yang panjang sebelum akhirnya dapat menjadi bagian dari masyarakat penganut Shinto kala itu. Pertumbuhan kedua agama ini menghasilkan suatu interaksi yang harmonis antara dewa-dewa kepercayaan Shinto dan dewa-dewa kepercayaan Budha. Seiring dengan berkembangnya kedua ajaran agama tersebut, maka bermunculan pula kuil-kuil yang dibangun untuk melakukan pemujaan dan melaksanakan ritual peribadatan. Kuil Shinto dikenal dengan sebutan jinja, sementara kuil Budha dikenal dengan sebutan otera. Dari masa ke masa kuil-kuil tersebut menjadi tempat yang banyak dikunjungi masyarakat Jepang, meskipun mereka bukan penganut dari kedua agama tersebut. Beragam alasan dikemukakan oleh mereka mengenai tujuan mereka mengunjungi kuil. Sebuah artikel yang ditulis Harming Suwarta (Mei,2016) menyebutkan bahwa orang datang ke kuil selain berdoa memohon kesehatan, berharap pekerjaan yang lebih baik juga untuk mencari penyembuhan spiritual dengan menenangkan diri di kuil.

Bagi mereka yang datang untuk berdoa pada dewa biasanya akan pulang membawa jimat yang dipercaya sebagai media perlindungan yang dikenal dengan sebutan omamori.

Bila dilihat dari sejarahnya omamori merupakan tradisi keagamaan yang berasal dari kepercayaan animisme dan pantheisme. Keberadaan tradisi ini sudah ada sejak zaman Tokugawa bahkan bertahan hingga di zaman modern ini. Kepopuleran omamori dalam masyarakat modern Jepang menimbulkan pertanyaan tersendiri. Di tengah kepesatan teknologi negara Jepang yang mampu menghasilkan peralatan canggih, masyarakatnya masih memegang teguh kepercayaan pada benda pelindung seperti omamori. Hal tersebut menjadi landasan dari penulis untuk memaparkan mengenai apa dan bagaimana omamori dalam kepercayaan masyarakat Jepang.

Pembahasan omamori sudah pernah dilakukan oleh mereka yang mempelajari tentang kejepangan. Wulan Dwi Savitri (2018), mahasiswa Universitas Sumatra Utara dalam skripsinya yang berjudul Fungsi dan Makna Omamori bagi Masyarakat Jepang menjelaskan bahwa berdasarkan fungsi dan maknanya yang beragam sebuah omamori dapat menjadi motivator bagi masyarakat Jepang untuk bekerja lebih giat agar berhasil dalam kehidupannya. Kemudian Fatonah (2018) dalam artikelnya yang berjudul Pemaknaan Jimat sebagai Simbol Religi bagi Mahasiswa Jepang, membahas tentang pengaruh omamori yang merupakan jimat dan simbol religi terhadap sikap dan perilaku masyarakat Jepang. Dari hasil analisisnya diketahui 
Kiryoku, Volume 3 No 22019

e-ISSN: 2581-0960 p-ISSN: 2599-0497

Tersedia online di http://ejournal.undip.ac.id/index.php/kiryoku

bahwa dalam masyarakat Jepang setidaknya ada 5 motif yang melandasi kepercayaan orang Jepang terhadap omamori. Sementara sikap dan perilaku masyarakat Jepang terhadap jimat mencerminkan konsep diri dan sikap tidak menyalahkan.

\section{METODE}

Metode yang digunakan dalam pembahasan omamori ini adalah studi pustaka. Pendekatan Studi pustaka digunakan untuk membuat analisa terhadap masalah yang dikaji dengan literatur sebagai sumber data primernya. Berikut ini beberapa langkah yang penulis lakukan.

1) Observasi : metode ini digunakan untuk mendapatkan gambaran mengenai kepercayaan yang dianut oleh masyarakat Jepang, meliputi sistem kepercayaan dan benda-benda yang mereka sakralkan. Gambaran yang diperoleh merupakan bahan / data primer yang akan ditelaah. Buku tentang berbagai sistem kepercayaan masyarakat Jepang digunakan sebagai data sekunder.

2) Klasifikasi: setelah diperoleh bahan yang cukup dilakukan klasifikasi bahan baik dari segi urgenitas maupun dari segi jenis bahan/data.

3) Analisa: dilakukan analisa dilakukan atas bahan yang sudah diperoleh dan diperkuat bahan/informasi dari buku yang sudah ada.

Data yang diperoleh dari hasil analisa kemudian dipaparkan dengan menggunakan metode deskriptif.

\section{HASIL DAN PEMBAHASAN}

\section{A. Kepercayaan Masyarakat Jepang}

Sebagian masyarakat di dunia beranggapan bahwa masyarakat Jepang tidak beragama. Namun demikian sebagian besar orang Jepang tetap mempunyai nilai spritualisme dengan pergi ke kuil untuk berdoa ataupun melaksanakan ritual yang telah menjadi kepercayaan turun temurun.Bila ditinjau dari perspektif sejarah, berkembangnya agama di Jepang tidak lepas dari pengaruh perkembangan agama di dunia yang berhubungan langsung dengan agama di Jepang. Dalam pemaparan Herlina $(2011 ; 114)$ disebutkan bahwa terdapat seorang peneliti keagamaan bernama Miyake Hitoshi yang menjelaskan mengenai agama di dunia yang berhubungan dengan agama di Jepang. Agama tersebut dapat dibagi menjadi beberapa kategori yaitu:

1) Mikai Shukyou, Agama Primitif. Contoh dari agama ini adalah animisme (kepercayaan terhadap roh dan gejalagejala alam); totemisme (keyakinan bahwa manusia memiliki hubungan dengan binatang); shamanisme, (kepercayaan terhadap adanya kekuatan dukun; dan shijo shinshinko, (agama yang percaya bahwa yang diyakini dan dipercayai hidup di langit).

2) Minzoku Shukyo yaitu agama rakyat atau agama negara yang hanya ada dalam satu bangsa saja. Contohnya yaitu Shinto, Tao, Yahudi dan lainnya.

3) Fuhen Shukyou yaitu agama-agama universal atau agama samawi, agamaagama yang dapat ditemukan dimana saja. Contohnya yaitu Islam, Kristen, Budha dan lainnya.

Kemudian dalam perkembangan selanjutnya meskipun dikatakan bahwa Shinto dan Budha menjadi kepercayaan yang paling dominan, namun dalam kehidupan sehari-hari nampaknya agama bukanlah sesuatu yang penting bagi mereka. Tidak heran bila pada umumnya orang Jepang dapat menganut lebih dari satu agama dan menjalankan ritualnya. Orang Jepang ketika lahir akan mendapatkan upacara dalam Shinto, ketika menikah mereka dapat memilih upacara dalam Shinto atau Kristen, dan pada saat upacara kematian atau penghormatan pada leluhurnya, mereka akan melaksanakannya dalam ritual agama Budha. Hal lain dapat kita lihat juga pada keseharian mereka saat 
mendatangi kuil keagamaan. Selain penempatan altar Shinto dan Budha ,adakalanya tempat mereka dihiasi pula dengan patung Bunda Maria. Orang Jepang pun dapat melakukan ritual doa baik di Jinja sebagai kuil shinto maupun di Otera yang merupakan kuil Budha. Pada hari raya lain seperti natal mereka pun akan ikut merayakannya dengan pergi ke gereja. Apa yang mereka lakukan tersebut dipenuhi sebagai sebuah kebutuhan untuk mengikuti ritual keagamaan yang berlangsung sepanjang tahun,sehingga kepercayaan mereka tidak dibatasi oleh satu agama saja.

Di luar agama Shinto dan Budha sebagai agama tradisional, saat ini banyak orang Jepang beralih ke berbagai gerakan keagamaan populer yang biasa dikelompokan dengan nama " agama agama baru" atau dalam bahasa Jepangnya disebut dengan shinshukyo. Agama-agama ini memiliki unsur-unsur Shinto, Budha dan takhayul lokal, dan sebagian telah berkembang untuk memenuhi kebutuhan sosial kelompokkelompok masyarakat. (Mulyadi,2017;17)

\section{B. Bentuk dan Jenis Omamori}

Dalam kehidupan masyarakat Jepang, kuil merupakan daya tarik yang cukup kuat untuk pemenuhan kebutuhan spiritualisme mereka. Kunjungan rutin mereka ke kuil diakui bukanlah sebuah pengakuan bahwa mereka seseorang yang beragama namun lebih kepada pemenuhan kebutuhan yang bersifat batiniah.Di kuil mereka memohon untuk keselamatan dan kesejahteraan hidup pada kamisama (dewa dalam kepercayaan Shinto). Selain melakukan ritual doa, masyarakat Jepang pun pada umumnya percaya pada keberkahan doa yang menjadi penjaga atau pelindung mereka dalam wujud sebuah jimat yang dikenal dengan sebutan omamori.
Secara denotatif dalam Kokugo Jiten (1991) omamori dijelaskan sebagai berikut :

お-まもり【。御守り】災難よけに 身につけるもの。特に、神社・寺 などの守り札。（Obunsha,1991； 157)

Omamori: Benda yang dibawa sebagai perlindungan dari ketidakberuntungan. Khususnya yang di dapat dari jinja atau tera.

Omamori tersebut pada umumnya berbentuk sebuah kantung terbuat dari kain berdekorasi dimana di dalam kain tersebut terdapat lipatan kertas atau potongan kayu yang bertuliskan nama dewa. Lipatan kertas tersebut sudah didoakan agar memberikan perlindungan dan keberuntungan pada si pemiliknya. Masyarakat Jepang percaya bahwa omamori adalah sebuah benda keramat yang menyimpan kekuatan dewa atau Budha.

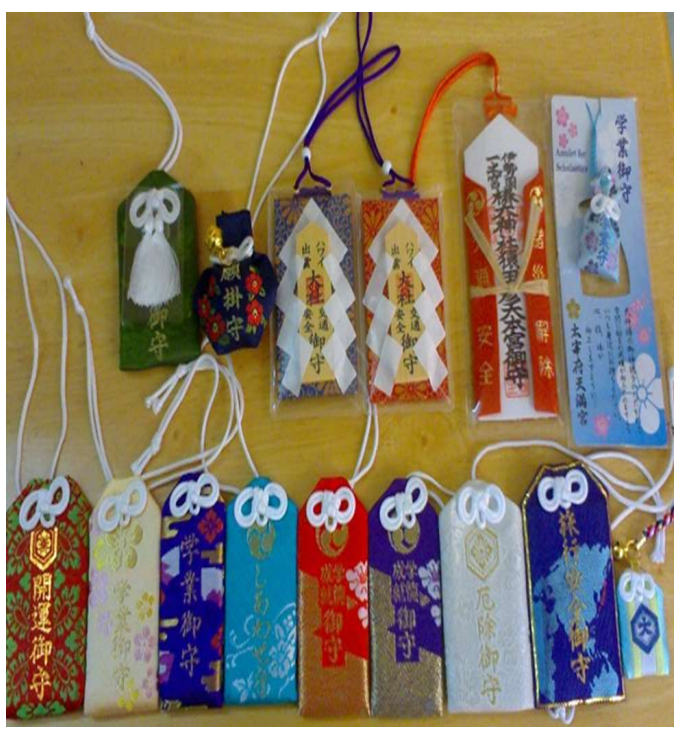

Gbr.1 Bentuk umum Omamori 


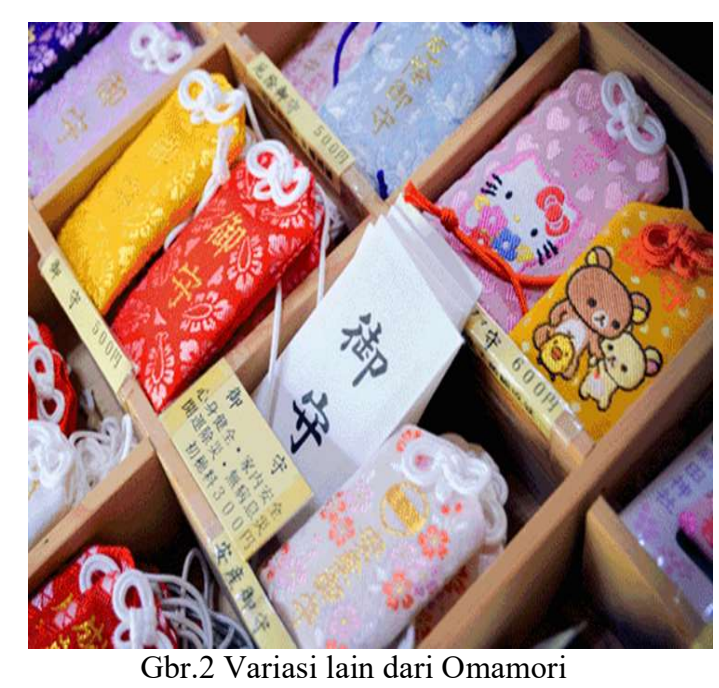

Omamori dipercaya membawa keberuntungan dan tersedia dalam berbagai nama untuk mendatangkan keselamatan dan nasib baik dalam berbagai tempat dan situasi. Dan orangorang percaya, jika pembungkusnya dibuka, maka jimat ini akan kehilangan kekuatan pelindungnya dan karena itulah jimat ini tak boleh dibuka. (https://www.tokyoweekender.com/2015/ 05/japanese-lucky-charms-the-guide-toomamori/)

Omamori yang dikenal juga dengan sebutan mamorifuda ini biasanya banyak dijual di jinja dan otera. Meskipun samasama menyediakan omamori namun terdapat perbedaan antara omamori dari jinja dan omamori dari otera. Dalam https://matcha-jp.com/id/1001 disebutkan bahwa omamori dari kuil Buddha mengandung banyak doa sementara omamori dari kuil Shinto didiami oleh roh para dewa.

Omamori pada umumnya berbentuk bungkusan kecil dengan kain berdekorasi,namun seiring dengan perkembangannya, di beberapa kuil terdapat bentuk lain dari omamori itu sendiri. Bentuk-bentuk omamori itu antara lain adalah :

1. Omamori berbentuk bandul,dikenal dengan sebutan kanemori
2. Omamori berbentuk daun teratai dengan hiasan kannon yang dikenal dengan sebutan rebbenmamori

3. Omamori dengan bentuk topeng Tengu

4. Omamori berupa lempengan kayu bergambar tumbuhan,bunga atau karakter dewa

5. Omamori berbentuk Kitsune (rubah putih) atau Maneki Neko (kucing) dengan hiasan lonceng

6. Omamori berbentuk boneka Daruma

7. Omamori dengan karakter modern, seperti karakter Hello Kitty, Mickey Mouse, Snoopy dan sebagainya.

Di Jepang sendiri jenis dari omamori cukup banyak. Namun yang umum digunakan oleh masyarakat Jepang sendiri terbagi dalam tujuh jenis sebagaimana yang akan penulis jelaskan berikut ini.

1. Yaku Yoke ( 厄除 ).

merupakan omamori yang dipercaya dapat melindungi pemiliknya dari gangguan setan atau hal-hal yang bersifat gaib.

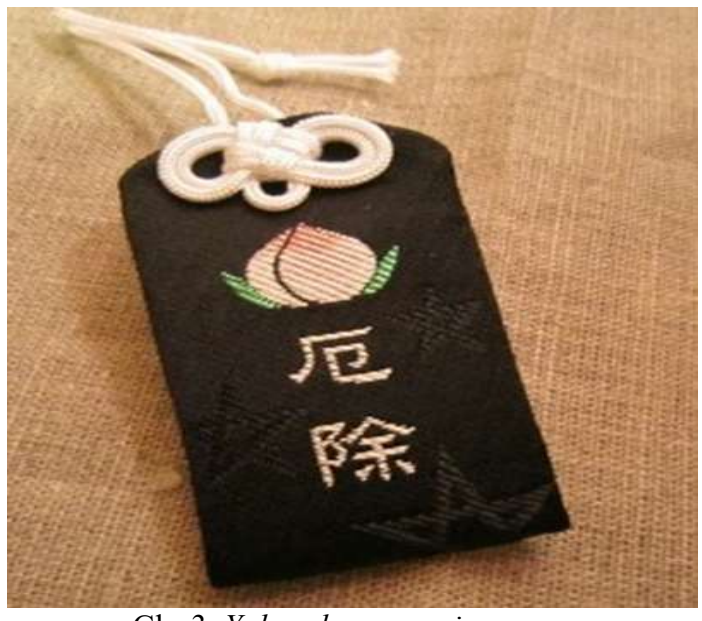

Gbr.3 Yakuyoke-mamori

\section{Kaiun (開運)}

Merupakan omamori yang dipercaya dapat membukakan pintu keberuntungan bagi pemiliknya. 
Kiryoku, Volume 3 No 22019

e-ISSN: 2581-0960 p-ISSN: 2599-0497

Tersedia online di http://ejournal.undip.ac.id/index.php/kiryoku

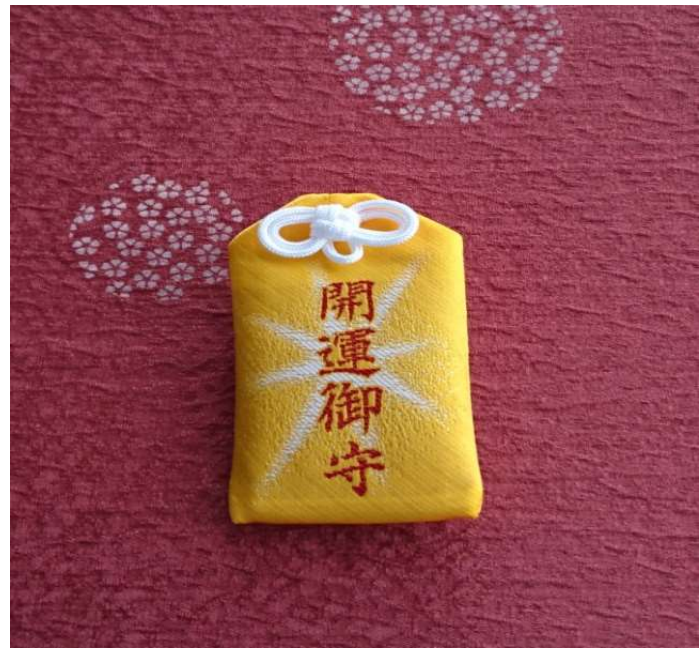

Gbr. 4 Kaiun-mamori

\section{Gakugyoujoju（学業成就）}

Merupakan omamori yang biasanya dibawa oleh para pelajar, mahasiswa ataupun pegawai. Jimat ini dipercaya dapat melancarkan pendidikan dan membuat pemiliknya dapat lulus pada saat ujian sekolah ataupun kerja.

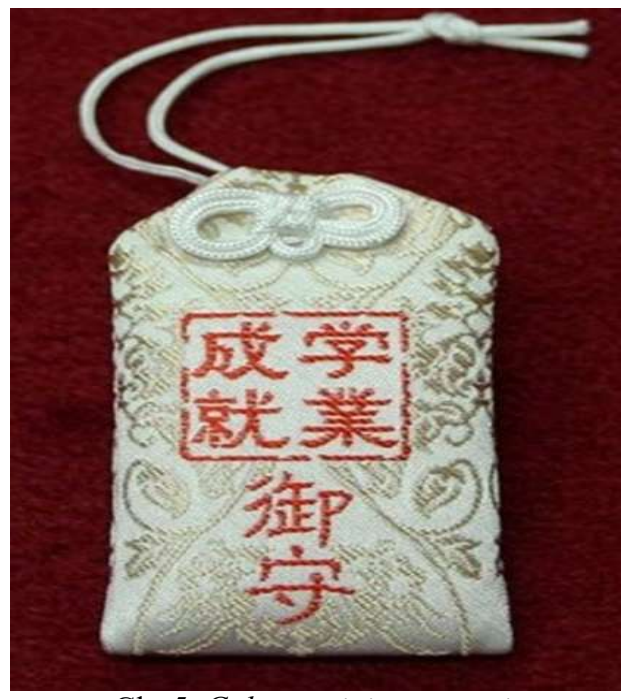

Gbr.5 Gakugyoujoju-mamori

4. Shoubai Hanjo (商売繫盛)

Merupakan omamori yang digunakan agar pemiliknya memperoleh kesuksesan dalam bisnis

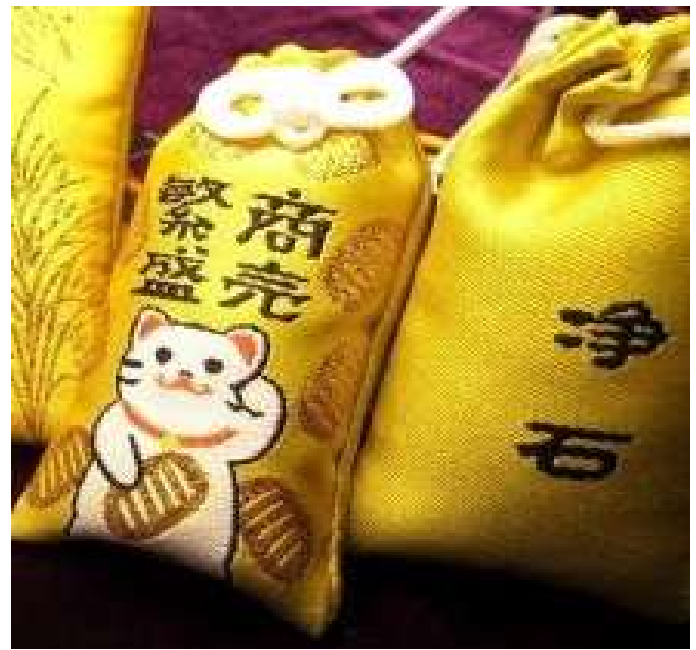

Gbr. 6 Shoubai Hanjo -mamori

\section{En Musubi ( 縁結び)}

Merupakan omamori yang dipercaya dapat membantu pemiliknya menemukan jodoh dan pernikahan.

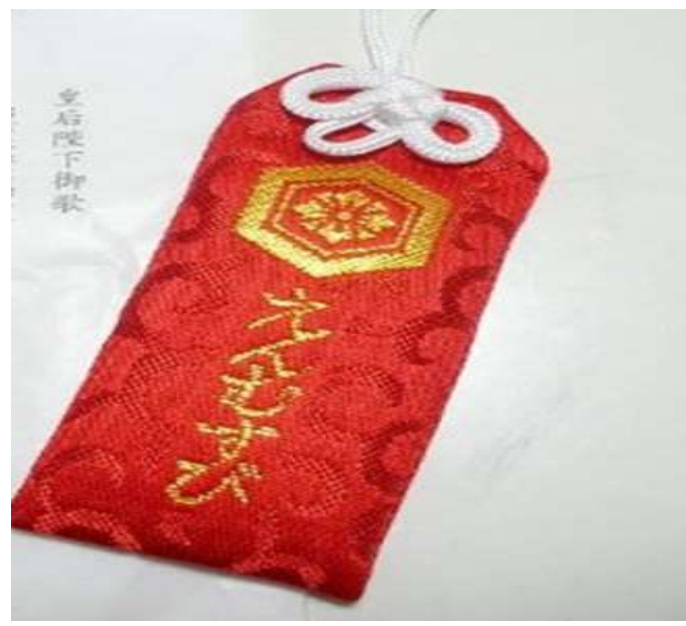

Gbr. 7 En Musubi-mamori

\section{Anzan (安産)}

Merupakan omamori yang dipercaya akan mendatangkan kesehatan kandungan dan kelancaran kelahiran. 
Kiryoku, Volume 3 No 22019

e-ISSN: 2581-0960 p-ISSN: 2599-0497

Tersedia online di http://ejournal.undip.ac.id/index.php/kiryoku

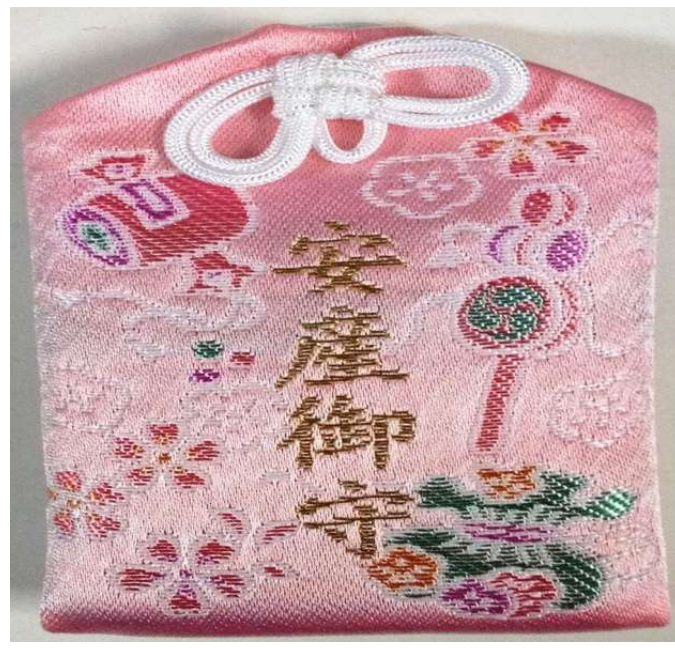

Gbr. 8 Anzan-mamori

7. Kotsuu Anzen （交通安全）

Merupakan omamori yang dipercaya untuk menjaga keselamatan pemiliknya pada saat melakukan perjalanan.

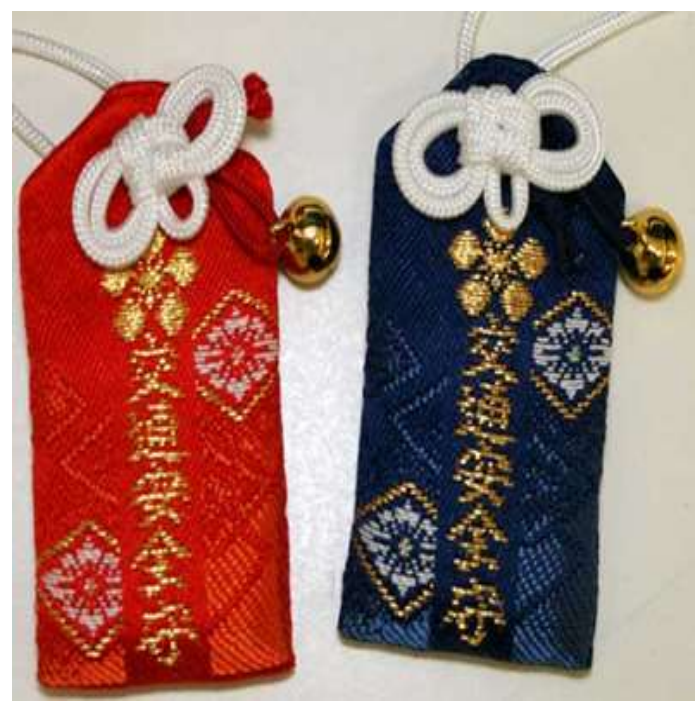

Gbr. 9 Kotsuu Anzen -mamori (matome.naver.jp)

\section{SIMPULAN}

Omamori merupakan sebuah bagian dari kepercayaan shinto yang telah dianut oleh masyarakat Jepang sejak ratusan tahun yang lalu. Keberadaan omamori menjadi simbol adanya kepercayaan masyarakat yang sangat kuat terhadap kekuatan dan keberadaan dewa dalam sebuah wujud benda kecil.

Dilihat dari jenis dan maknanya omamori menjadi bagian harapan dan doa masyarakat Jepang dalam melalui siklus kehidupannya dari mulai doa dan harapan ketika seorang manusia dilahirkan, menempuh kehidupan sebagai anggota masyarakat hingga harapan untuk diberikan kesehatan dan keselamatan sampai akhir hayat mereka.

\section{DAFTAR PUSTAKA}

Anonim. (1998). The Kondansha Bilingual Encyclopedia of Japan. Tokyo : Kondansha International Ltd.

Adnura. (2012). Ofuda dan

Omamori.Retrieved from

http://mittsu-

sekai.blogspot.com/2012/05/ofuda. $\underline{\text { html }}$

Endraswara, Suwardi. (2006). Metodologi Penelitian Kebudayaan. Jogjakarta : Gajah Mada University Press

Fatonah (2018) Pemaknaan Jimat sebagai Simbol Religi bagi Mahasiswa Jepang, Jurnal Komunikasi Global $7(1)$

Harming Suwarta, Thomas. (2016). Spiritualitas Negeri Sakura. Artikel pada Surat Kabar Media Indonesia. Retrieved from http://mediaindonesia.com/read/det ail/48082-spiritualitas-negerisakura

Herlina,Sandra. (2011). Suatu Telaah Budaya : Agama dalam Kehidupan Orang Jepang. Jurnal Al-Azhar Indonesia Seri Humaniora. 1 (2)

Jacobsen, Natalie. (2015). Japanese Lucky Charm : A Guide to Omamori. Retrieved from 
https://www.tokyoweekender.com/ 2015/05/japanese-lucky-charms-

the-guide-to-omamori/

Matsumura, Akira. (1991). Kokugo Jiten. Tokyo:Obunsha.

Mulyadi, Budi. (2017).Konsep Agama dalam Kehidupan Masyarakat Jepang. Jurnal Izumi 1 (1)

Savitri, Wulan Dwi (2018). Fungsi dan Makna Omamori bagi Masyarakat Jepang.

Retrieved

from http://repositori.usu.ac.id/han dle/123456789/2975

\section{Sumber Internet :}

https://matcha-jp.com/id/1001 Diunduh tanggal 26 Februari 2019

https://japanesestation.com/. Diunduh tanggal 20 Mei 2019

https://www.yaku-yoke.com. Diunduh tanggal 10 Juni 2019

http://www.tarobo.sakura.ne.jp. Diunduh tanggal 10 Juni 2019

https://matome.naver.jp. Diunduh tanggal 10 Juni 2019 